\title{
Multi Purpose Crew Vehicle Environmental Control and Life Support Development Status
}

\author{
John F. Lewis ${ }^{1}$, Richard A. Barido ${ }^{2}$, and Cynthia D. Cross ${ }^{3}$. \\ NASA Johnson Space Center, Houston, Texas, 77058 \\ Robyn Carrasquillo ${ }^{4}$ \\ NASA Marshal Space Flight Center, Huntsville, Alabama, 35812 \\ and \\ George Edward Rains ${ }^{5}$ \\ Jacobs Engineering, Houston, Texas, 77058
}

\begin{abstract}
The Orion Multi Purpose Crew Vehicle (MPCV) is the first crew transport vehicle to be developed by the National Aeronautics and Space Administration (NASA) in the last thirty years. Orion is currently being developed to transport the crew safely from the Earth beyond Earth orbit. This year, the vehicle focused on building the Orion Flight Test 1 (OFT1) vehicle to be launched in 2013. The development of the Orion Environmental Control and Life Support (ECLS) System, focused on the components which are on OFT1 which includes pressure control and active thermal control systems, is progressing through the design stage into manufacturing. Additional development work was done to keep the remaining component progressing towards implementation for a flight test in 2017. This paper covers the Orion ECLS development from April 2011 to April 2012.
\end{abstract}

${ }^{1}$ Orion ECLS System Manager, EC6/Crew and Thermal Systems Divison

${ }^{2}$ Orion ECLS ARS Subsystem Manager, EC6/Crew and Thermal Systems Divison

${ }^{3}$ Orion ECLS ATCS Subsystem Manager, EC6/Crew and Thermal Systems Divison

${ }^{4}$ Orion Crew and Thermal FAM, Systems Development, Integration, and Test, ES62. AIAA Member

${ }^{5}$ Orion ECLS PSC Subsystem Manager, EC6/Crew and Thermal Systems Divison. 